\title{
A PROPOSAL FOR GENERALIZATION of 3D MODELS
}

\author{
A. Uyar ${ }^{1, *}$, N. N. Ulugtekin ${ }^{2}$ \\ ${ }^{1}$ OMU, Engineering Faculty, Geomatics Engineering, 55139 Atakum, Samsun azize.uyar@omu.edu.tr \\ ${ }^{2}$ ITU, Civil Engineering Faculty, Geomatics Engineering 80626 Maslak Istanbul, Turkey ulugtek@itu.edu.tr
}

KEY WORDS: 3D models, generalization, LoDs, MRDB, CityGML

\begin{abstract}
:
In recent years, 3D models have been created of many cities around the world. Most of the 3D city models have been introduced as completely graphic or geometric models, and the semantic and topographic aspects of the models have been neglected. In order to use 3D city models beyond the task, a generalization is necessary. CityGML is an open data model and XML-based format for the storage and exchange of virtual 3D city models. Level of Details (LoD) which is an important concept for 3D modelling, can be defined as outlined degree or prior representation of real-world objects. The paper aim is first describes some requirements of 3D model generalization, then presents problems and approaches that have been developed in recent years. In conclude the paper will be a summary and outlook on problems and future work.
\end{abstract}

\section{INTRODUCTION}

\subsection{General Informations}

Map is an abstraction of reality and fundamental language of geography, also symbolize image of geographical reality. The symbols, directions, lines and legend all require some understanding before to start reading a map effectively. Earth's minimized model representation is provided through maps as two or three dimensional. To understand maps and extract information of them, maps must be accurate and made according to certain rules, therefore, design stage is significant (Uluğtekin and Doğru, 2005; Uluğtekin and İpbüker, 1996).

2D systems for mapping are widely used in geographic information system (GIS), but are limited in solving complex problems. The real world has three dimensions, therefore the man's brain can interpret 3D images more successfully. 3D city models make it easier for people to understand the spatial properties of urban objects. 3D city models have already been widely employed to assist different applications such as urban planning, traffic control, mobile telecommunication design, etc. (Ulugtekin and Dogru, 2005; Sahillioglu, 2015).

This paper aim is combining the Levels of Detail (LoD) in the CityGML structure and Multiple Representation Database MRDB representation levels. Thereby, this combination can be used for approach to some of generalization problems. This study describes generalization, 3D models, and generalization problems of 3D models, MRDB and LoD. Then this paper propose a schema for 3D building generalization (Uyar and Ulugtekin, 2017).

\subsection{Generalization}

The purpose of generalization is to reduce the complexity of a data set with respect to its size and semantic content while retaining the pieces of information, and this information is relevant to the task and for users (Doğru and Uluğtekin, 2009). Generalization contains several operators such as simplification, smoothing, aggregation, amalgamation, collapse, selection, typification, exaggeration, enhancement, classification, displacement. (Shea and McMaster 1989).

The purpose of generalization is therefore to reduce the size and semantic complexity of a model to a level that can be handled by the application without losing relevant information. Process of generalization strongly depends on the application, aim and scale of the model (Guercke et al., 2009)

Representation and generalization of 3D models are the keys to efficient visualization of multi-scale 3D city models. Until now there are two type of generalization; object and cartographic generalization. Therefore 3D models, there is one more type which is model generalization (Lee and Hardy, 2005, Guercke et al., 2009). To reduce the 3D data volume and increase the visualization efficiency, various generalization methods are investigated. Technically, requisites of 3D generalization are: methods to automatically generate different LoDs; MRDB and functionalities to automatically select the optimal LoD for a given application; these requisites have to be automate the generalization process with the aim of analyzing building models in different scales (Baig and Rahman, 2013; Baig and Alizadehashrafi, 2014).

\subsection{D Modelling}

Nowadays, a rapidly increasing number of companies create virtual 3D city models for use in various markets, such as urban planning, telecommunications, disaster/crisis management, 3D cadastre, tourism, navigation, facilities management, environmental simulations and smart cities applications. 3D city models will play an increasingly important role in our daily lives and become an essential part of the modern city information infrastructure (Gröger et al., 2012).

2D systems are widely used in geographic information system (GIS), but are limited in solving complex problems. 3D city models make it easier for people to understand the spatial properties of urban objects. The current popular GIS software

\footnotetext{
* Corresponding author
} 
handles, manipulates, and analyses geographic data in $2 \mathrm{D}$ or $2.5 \mathrm{D}$, thus using this system to manipulate $3 \mathrm{D}$ data information about real world objects may not be appropriate. Therefore, the 2D GIS (or 2.5D GIS) needs to be extended, i.e. to 3D GIS. Similar to the 2D cartographic maps, the 3D city models be used to integrate various data from different sources for public accessible visualisation and many other applications. 3D city models are the basis of many applications and are the platform for integrating city information from different resources (Raper, 1989; Adami and Guerra, 2006).

In 3D city modelling, the concept of level-of-details indicates the methods of collecting data for a certain application. The levels of details are of great use to data analysis and mental visualization. Visualisation is a complex and important issue in 3D city model applications. Many applications such as urban planning, facility management and personal navigation require semantic information about the city objects besides the geometry models. It is essential to develop methods for 3D city model semantic information modelling, representation, discovering, management, querying and analysis (Kolbe et al., 2005; Kolbe 2009).

\subsection{D Generalization Problems}

3D city models are not only geometrically representation of urban areas but also compound geometric a land thematic features of spatial details and also 3D city models can be used for spatial analyses. When you create 3D models listed problems encountered (Sester, 2007; Mao, 2011; Baig et al., 2013).

- $\quad$ Different users need different models

- Detailed models cannot be displayed in real time

- $\quad$ Huge amount of data

- Different source of data

- Geometrical and semantically relation

Associated with development of GIS related technologies such as Global Positioning System (GPS), and remote sensing, the volume of raw data especially for 3D city models is increased dramatically. These data are also required to be updated constantly or even in real-time. It is impossible to manually maintain real-time updated multi-scale representations for such amount of data for a city, not to mention for a country (Götzelmann et al., 2009). However, because to storage and processing power are very limited, the amount data delivered from digital map providers has to be reduced drastically. A direct transfer of the techniques from computer graphics to process semantically rich topographic objects often is not possible, as these techniques mostly reduce the amount of data only based on geometric criteria without taking semantics into account (Sester, 2007).

\section{MRDB and LoD}

\subsection{MRDB}

Multi-representation databases (MRDB) allow representing the same real world entities in different cartographic databases with their own level of detail. In a MRDB, different views on the same physical objects or phenomena can be stored and linked (Basaraner, 2009; Doğru and Ulugtekin, 2009). This variety of sights can result from different views of the world, different applications, as well as different resolutions. These lead to differences in the objects as such, i.e. in the semantics and in the geometry (Hampe et al., 2003, Sester, 2007; Burghardt et al., 2010). Generally, there are four MRDB levels for building showed by figure 1 (Kilpelainen, 1997).

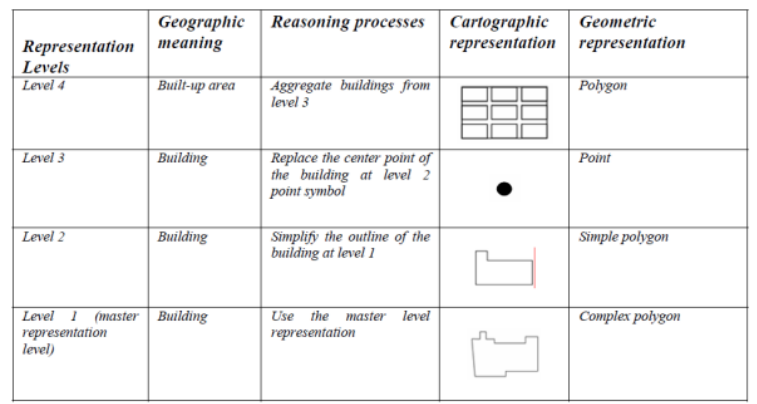

Figure 1. MRDB levels (Kilpelainen 1997).

\subsection{CityGML' LoD}

Several standards have been introduced to enable the 3D model to be used effectively together with its widespread use and to be understood by all. CityGML is one of them, also most used one. CityGML is a common information model for the representation of 3D urban objects. CityGML covers broad thematic fields of city objects, from geometrical band topological to semantic aspects. CityGML, the OGC standard to represent 3D city models, can be used to integrate both geometric and semantic information of the city models (Kolbe, 2009; Biljecki, 2013).

CityGML defines not only the shape and photo-realistic appearance of 3D building objects but also thematic properties, attached rich semantic information can also be stored in CityGML. These models are reconstructed and represented in different LoDs to be used for visualization purposes. There are two main advantages of CityGML. Firstly, components such as outer shell, openings (windows, doors), outer building installations, interiors (chair, table, fan etc) can be modeled, represented and stored in multiple LoDs. Secondly, generalization specifications provided for different LoDs are characterized by differing accuracies and minimal dimensions of objects. There are five LoD in CityGML standards for building (figure 2) (Gröger et al., 2012; OGC 2008).

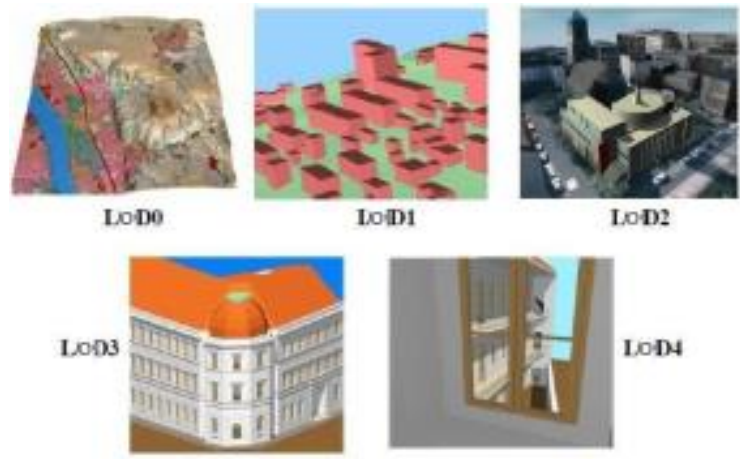

Figure 2. LoDs of CityGML (Gröger et al., 2012).

The coarsest level LoD0 is essentially a two and a half dimensional Digital Terrain Modeln LoD1 the buildings can be observed as blocks having flat roofs. The LoD2 includes the structures of the roofs and external installa $\neg$ tions such as windows, and chimneys. LoD3 displays architectural models 
with details of the roofs, walls, balconies and etc. LoD4 is the last and most comprehensive level of details, and includes the internal structure of the buildings such as the rooms, furniture, domestic installations, etc. (OGC, 2008; Gröger et al., 2012; Baig and Alizadehashrafi, 2014).

\subsection{Combination MRDB and CityGML' LoD}

In this study, it is suggested and explored that combining the LoDs in the CityGML detail level and MRDB levels for more useful systems can be created for automatic generalization. When the concepts of MRDB levels and LoDs are combined for the 3D city model, firstly figure is formed. In Figure 3, where the CityGML levels are received as the level of detail (LoD), the LoDs concept are combined with the levels of representation in the MRDB.

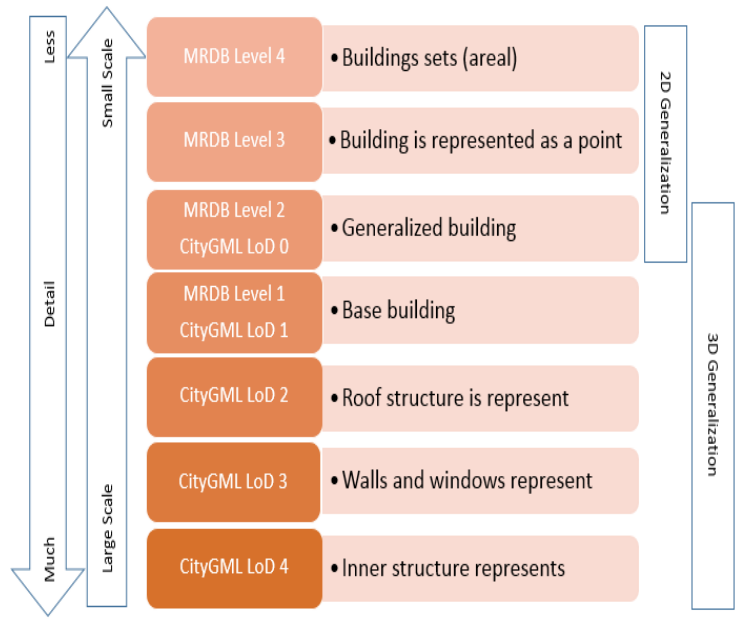

Figure 3. MRDB representation levels and CityGML detail levels for building object.

The first level of MRDB and the LoD 0 representations maintain the same (basic) geometric substructure base. In general, MRDB display levels and LoD levels of detail have shown the purpose of detailing and generalization in relation to the scale. In Figure 4 building example, Figure 1 and Figure 2 are combined. These relationships are graphically shown in Figure 4.

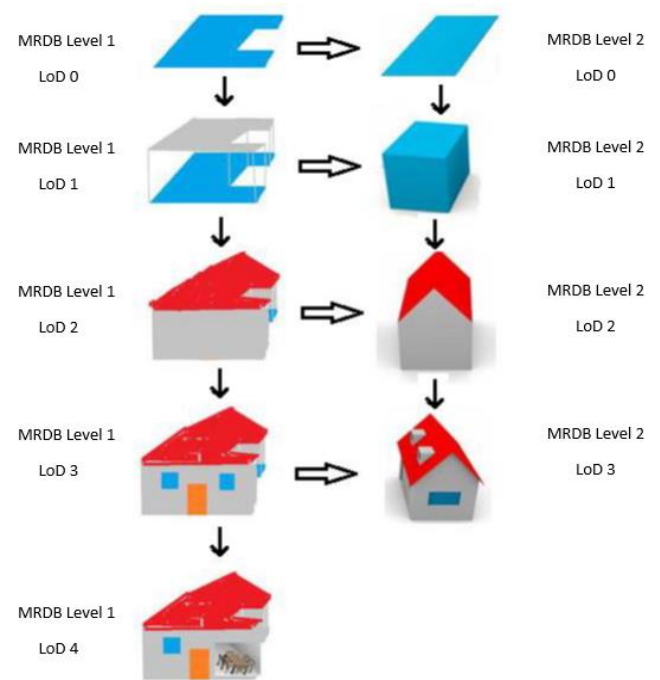

Figure 4. Combination of Figure 1 and Figure 2 for buildings.
In Figure 5, MRDB levels and detail level (LoD) are paired individually. For this reason, some MRDB levels do not contain sufficient detail, so LoD detail levels are not associated.

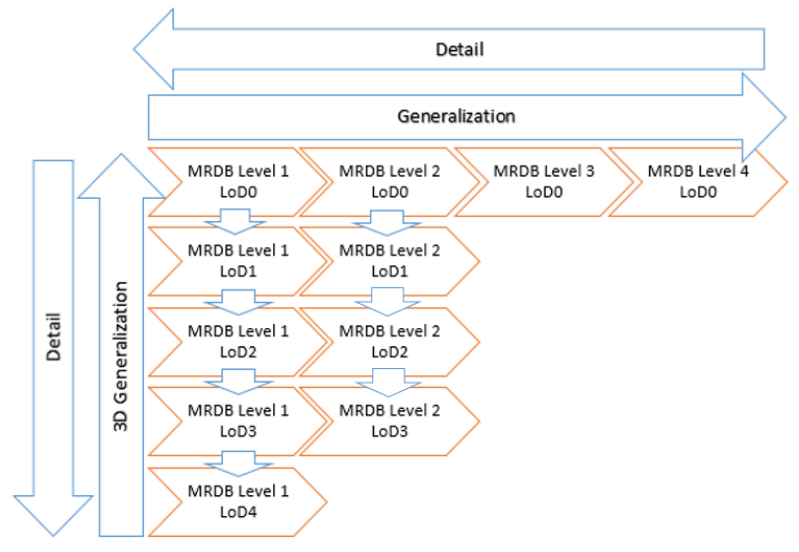

Figure 5. MRDB levels and LoDs for buildings.

\section{CONCLUSIONS}

In this study, for automatic generalization, data management and store MRDB levels and CityGML LoDs are combined. In future works, these concepts will be implemented according to semantic information. For the semantic generalization, the objects firstly needs to be classify according to the aim of 3D. Depending on these classifications, the marking at the desired level of detail and display level must be specified. This can be improved by researching the subject in full with semiology, cartography and related science(s). 3D semantic generalization should be considered as versatile. The work on this subject will be research continued by the author(s).

\section{REFERENCES}

Adami A.; Guerra, F., 2006. 3D Digital Maps: New Development in Cartography for Cultural Heritage, ePerimetron 1(2), pp. 164-169.

Baig, S. U., Alizadehashrafi, B., 2014. 3D Generalization of Boundary Representation (B-Rep) of Buildings, FIG Congress 16 - 21 June Engaging the Challenges, Enhancing the Relevance Kuala Lumpur, Malaysia.

Baig, S. U., Rahman, A. A., 2013. A Three-step Strategy for Generalization of 3D Building Models Based on CityGML Specifications, GeoJournal 201378 pp. 1013-1020.

Başaraner, M., 2009. Çok Çözünürlüklü Mekansal Veri Tabanları. Akademik Bilişim'09 - XI. Akademik Bilişim Konferansı Harran University, Şanlıurfa, 11-13 Februrary

Biljecki, F., 2013. The Concept of Level of Detail in 3D City Models, Delft Univesity of Technology, GISt Report No. 62, ISSN: 1569-0245.

Burghardt, D., Petzold, I., Neun, M., Weibel, R. 2010. MultiRepresentation Databases with Explicitly Modelled Horizontal, Vertical and Update Relations, The Cartographic Journal Vol. 47 No. 3 pp. $238-249$ August. 
Doğru, A.Ö., Uluğtekin, N., 2009. Araç Navigasyon Haritası Tasarımı İçin Yol Genelleştirmesi, ITÜ̈ Mühendislik Dergisi, Vol. 8, No. 3, pp. 109-119.

Götzelmann, T., Guerke, R., Brenner, C., Sester, M., 2009. Terrain-Dependent Aggregation of 3D City Models. In: ISPRS Workshop on quality, scale and analysis aspects of city models, Lund, Sweden, 3-4 December.

Gröger, G., Kolbe, T. H., Nagel, C., Hafele, K. H., (Eds.) 2012 OGC City Geography Markup Language (CityGML) Encoding Standard [Online]. Available: http://www.opengis.net/spec/citygml/2.0 (28.05.2017).

Guercke, R., Brenner, C., Sester, M. 2009. Generalization of Semantically Enhanced 3D City Models, ISPRS Workshop Commission GeoWeb 27-31 July, Vancouver, Canada.

Hampe, M., Anders, K. and Sester, M. 2003. MRDB Applications for Data Revision and Real Time Generalization, 21st International Cartographic Conference (ICC) 10-16 August, Durban, South Africa.

Kilpelainen, T., 1997. Multiple Representation and Generalization of Geo-databases for Topographic Maps, Doctoral Thesis, Finnish Geodetic Institute, Finlandia.

Kolbe, T. H., Gröger, G., Plümer, L., 2005. CityGML Interoperable Access to 3D City Models, Int. Symposium on Geo-information for Disaster Management on 21.-23. March Delft.

Kolbe, T. H., 2009. 3D Geo-information Sciences. Part I, Representing and Exchanging 3D City Models with CityGML. Berlin: Springer Berlin Heidelberg, Available from: http://link.springer.com/chapter/1 0.1007\%2F978-3-540-873952_2.

Lee, D., Hardy, P., 2005. Automating Generalization Tools and Models, Proceedings of the International Cartographic Conference (ICC), 11-16 July, Spain.

Mao, B., 2011. Visualisation and Generalisation of 3D City Models, Doctoral Thesis, Royal Institute of Technology (KTH) Department of Urban Planning and Environment.

OGC, 2008. OpenGIS City Geography Markup Language (CityGML) Encoding Standard, OGC project document no: OGC 08-007r1, G. Gröger, T. H. Kolbe, A. Czerwinski and C. Nagel (Eds.), Retrieved from: http://www.opengeospatial.org/standards/citygml

Raper, J. (ed.). 1989. Three Dimensional Applications in Geographic Information Systems. Pp. 189, Taylor \& Francis Ltd., London.

Sahillioğlu, Y., (2015). 3 Boyutlu Modelleme ve Analiz, ODTÜ Bilgisayar Topluluğu Elektronik Dergisi, Nisan, e-dergi http://e-bergi.com/y/3Bmodelleme- analiz.

Sester, M., 2007. 3D Visulation and Generalization, Photogrammetric Week '07 Wichmann Verlag, Heidelberg, pp. 285-295.

Shea, K. S., McMaster, R., 1989. Cartographic Generalization in a Digital Environment: When, and How to Generalize, AutoCarto 9, Baltimore, pp. 56-67.
Uluğtekin, N., Doğru, A. Ö., 2005. Coğrafi Bilgi Sistemi ve Harita: Kartografya. pp. 209-215, Ege Üniversitesi CBS Sempozyumu, İzmir.

Uluğtekin, N., İpbüker, C., 1996. Coğrafi Bilgi Sistemi ve Kartografya, CBS Sempozyumu, Yıldız Teknik Üniversitesi, İstanbul.

Uyar A., Ulugtekin N. N., 2017. Generalization Problems of 3D Models and LoD Concept, 28th International Cartographic Conference, 2-7 July, Washington, USA. 